\title{
Rios urbanos e o poder público: o caso do rio Verruga em Vitória da Conquista, Bahia, Brasil, na segunda metade do século $\mathrm{XX}$
}

\section{Urban rivers and public authority: the case of the Verruga river in Vitória da Conquista, Bahia, Brazil, in the second half of the $20^{\text {th }}$ century}

\section{Luisa Prazeres Vasconcelos}

Universidade Estadual do Sudoeste da Bahia (UESB)

Vitória da Conquista, Brasil

luisavasconcelos@hotmail.com

(iD) 0000-0001-9792-774X

\section{Felipe Eduardo Ferreira Marta}

Universidade Estadual do Sudoeste da Bahia (UESB)

Vitória da Conquista, Brasil

Universidade Estadual de Santa Cruz (UESC)

Ilhéus, Brasil

fefmarta@uesc.br

(iD) 0000-0002-0501-4298

\section{Información del artículo}

Recibido: 5 agosto 2020

Revisado: 14 enero 2021

Aceptado: 10 febrero 2021
ISSNe 2340-7743

DOI

10.17561/AT.19.5702 (c) $\mathrm{CC}-\mathrm{BY}$

(C) Universidad de Jaén (España). Seminario Permanente Agua, Territorio y Medio Ambiente (CSIC)

\section{RESUM 0}

O objetivo deste texto consiste em discutir a gestão das águas do rio Verruga, pelo poder público local, ao analisar o processo de urbanização em Vitória da Conquista, Bahia, Brasil, na segunda metade do século XX. Nesse sentido, consideraramse, para a pesquisa, as ações empreendidas por José Fernandes Pedral Sampaio, ex-prefeito e liderança política no município, a partir da análise de uma entrevista coletada no ano 2000, através da metodologia da história oral. Buscou-se com este procedimento, investigar, através dos fragmentos da memória contida na entrevista, as modificações que foram realizadas no leito do rio e relacioná-las à malha urbana atual da cidade. Os resultados trazem indícios de como as ações do poder público exerceram um papel decisivo na relação entre a cidade de Vitória da Conquista e o rio Verruga.

PALAVRAS-CHAVE: Memória, Rio, Cidade, Gestão urbana, Expansão urbana.

\section{ABSTRACT}

The purpose of this article is to discuss the water management of the Verruga river by the local government when analyzing the urbanization process in Vitória da Conquista, Bahia, Brazil, in the second half of the 20th century. In this sense, the actions taken by José Fernandes Pedral Sampaio, former mayor and political leadership in the municipality, were considered for the research, based on the analysis of an interview collected in 2000 using the oral story methodology. This procedure sought to investigate through the fragments of the memory contained in the interview, the changes that were made in the riverbed and relate them to the current urban fabric of the city. The results provide evidence of how the actions of the public authorities played a decisive role in the relationship between the city of Vitória da Conquista and the Verruga River. 
Ríos urbanos y poder público: el caso del río Verruga en Vitória da Conquista, Bahia, Brasil, en la segunda mitad del siglo XX

\section{RESUMEN}

El objetivo de este trabajo es discutir la gestión del agua del río Verruga por parte del gobierno local al analizar el proceso de urbanización en Vitória da Conquista, Bahía, Brasil, en la segunda mitad del siglo XX. En este sentido, se consideraron para la investigación las acciones tomadas por José Fernandes Pedral Sampaio, exalcalde y líder político del municipio, a partir del análisis de una entrevista recogida en el año 2000 utilizando la metodología de la historia oral. Con este procedimiento, buscamos investigar a través de los fragmentos de la memoria contenida en la entrevista, los cambios que se hicieron en el lecho del río y relacionarlos con el tejido urbano actual de la ciudad. Los resultados proporcionan evidencia de cómo las acciones de las autoridades desempeñaron un papel decisivo en la relación entre la ciudad de Vitória da Conquista y el río Verruga.

PALABRAS CLAVE: Memoria, Río, Ciudad, Gestión urbana, Expansión urbana.

Fleuves urbains et puissance publique: le cas de la rivière Verruga à Vitória da Conquista, Bahia, Brésil, dans la seconde moitié du XX siècle

\section{RÉSUMÉ}

L'objectif de ce travail est de discuter de la gestion de l'eau de la rivière Verruga par le gouvernement local lors de l'analyse du processus d'urbanisation à Vitória da Conquista, Bahia, Brésil, dans la seconde moitié du XXe siècle. En ce sens, les actions menées par José Fernandes Pedral Sampaio, ancien maire et dirigeant politique de la commune, ont été prises en compte pour l'enquête, sur la base de l'analyse d'un entretien recueilli en 2000 selon la méthodologie de l'histoire orale. Avec cette procédure, nous cherchons à enquêter à travers les fragments de mémoire contenus dans l'interview, les changements qui ont été effectués dans le lit de la rivière et à les relier au tissu urbain actuel de la ville. Les résultats démontrent comment les actions des autorités ont joué un rôle décisif dans la relation entre la ville de Vitória da Conquista et la rivière Verruga.
Fiumi urbani e potere pubblico: il caso del fiume Verruga a Vitória da Conquista, Bahia, Brasile, nella seconda metà del XX secolo

\section{SOMMARIO}

Lo scopo di questo testo è discutere la gestione dell'acqua del fiume Verruga, da parte del governo locale, durante l'analisi del processo di urbanizzazione a Vitória da Conquista, Bahia, Brasile, nella seconda metà del XX secolo. In questo senso, sono state prese in considerazione per la ricerca le azioni intraprese da José Fernandes Pedral Sampaio, ex sindaco e dirigente politico del comune, sulla base dell'analisi di un'intervista raccolta nel 2000, utilizzando la metodologia della storia orale. Con questo procedimento si è cercato di indagare, attraverso i frammenti della memoria contenuti nell'intervista, i mutamenti che si sono verificati nell'alveo e di metterli in relazione con l'attuale tessuto urbano della città. I risultati forniscono la prova di come le azioni del governo abbiano svolto un ruolo decisivo nel rapporto tra la città di Vitória da Conquista e il fiume Verruga.

PAROLE CHIAVE: Memoria, Fiume, Vittà, Gestione urbana, Espansione urbana. 


\section{Introdução}

As crescentes inundações que diversos centros urbanos brasileiros têm vivenciado, nos últimos anos, com consequentes destruições das infraestruturas e perdas humanas, nos obriga a repensar o nosso modelo de conceber cidades, adotado ao longo do século XX. Analisando-se a relação que foi estabelecida entre a malha urbana e os elementos da paisagem natural, nas urbes em constante expansão, pode-se perceber que, na maior parte dos casos, não se soube lidar com os fluxos da natureza nos territórios ocupados pelas cidades.

Neste texto, estudaremos o caso de Vitória da Conquista, uma cidade estabelecida aos pés da Serra do Periperi, ocupando um planalto no interior do estado da Bahia, no Brasil, onde, em sua área urbana central, nasce o rio Verruga. 0 município está localizado a sudoeste da capital do estado, Salvador, com uma população estimada em 2018 de 338.885 habitantes e caracterizado como uma capital regional, cuja região de influência engloba 88 cidades, incluindo norte do estado de Minas Gerais, atendendo a uma população de 2.015 .833 habitantes ${ }^{1}$. Para melhor se estudar a evolução urbana da cidade e a relação que foi estabelecida com o rio, mostrou-se fundamental relacioná-las às decisões tomadas pelo poder público durante sua expansão.

Vitória da Conquista passou a vivenciar o adensamento de sua malha urbana nas primeiras décadas do século $\mathrm{XX}^{2}$, fato que foi compartilhado por tantas outras cidades brasileiras, e que consistiu em um reflexo do modelo industrial adotado pela sociedade a partir do século $\mathrm{XIX}^{3}$. Porém, por se tratar de uma cidade relativamente nova, tendo em vista que sua emancipação política ocorreu apenas em $1840^{4}$, e por estar distante quase $500 \mathrm{~km}$ da capital do estado, a área urbana de Vitória da Conquista era pouco expressiva até a década de 1940. Entre as décadas de 1940 e 1980, a sua dimensão foi ampliada significativamente, com sua área urbanizada passando a abranger um raio de $7 \mathrm{~km}-18$ vezes maior que os $400 \mathrm{~m}$ de raio que podia ser percebido 40 anos antes ${ }^{5}$.

Nesse processo de urbanização, o líder político José Fernandes Pedral Sampaio foi peça fundamental na organização do espaço urbano. Conhecido apenas pelo sobrenome Pedral, o político foi prefeito de Vitória da Conquista por três períodos, na segunda metade do sé-

\footnotetext{
1. Instituto Brasileiro de Geografia e Estatística (IBGE), 2020, 50.

2. Ferraz, 2001, 31.

3. Santos, 1993, 26-27.

4. Viana, 1982, 122.

5. Prefeitura Municipal de Vitória da Conquista (adiante PMVC), 2019, 70-71.
}

culo XX, e assessorou outros três mandatos de prefeitos vinculados à sua base política, totalizando 25 anos no poder, direta e indiretamente, dos quais, 24 anos se deram de forma ininterrupta, entre 1973 e 1996.

Através da análise de um depoimento colhido em entrevista com o antigo prefeito, no ano 2000, utilizando o método da história oral, busca-se interpretar o olhar subjetivo, presente na memória desta importante personagem, sobre a importância histórica do rio Verruga e como os seus planos para a cidade incorporaram este curso d'água.

Sobre as características e as possibilidades do uso da entrevista como fonte de pesquisa, destacamos que estes relatos consistem em uma rememoração de fatos passados, sob a ótica do presente e "através desse trabalho de reconstrução de si mesmo o indivíduo tende a definir seu lugar social e suas relações com os outros"6.

A entrevista de história oral suscita a estruturação do pensamento individual de forma a refazer sua própria identidade, a partir de uma memória comum aos grupos da sociedade dos quais o indivíduo participa. Esta memória dos grupos sociais foi conceituada pelo sociólogo Maurice Halbwachs como uma memória coletiva, onde afirma que "cada memória individual é um ponto de vista sobre a memória coletiva, que este ponto de vista muda conforme o lugar que ali eu ocupo, e que este lugar mesmo muda segundo as relações que mantenho com outros meios"7.

Nesse sentido, em última análise, tomamos a entrevista como um fragmento da memória de José Pedral, referente ao ano de 2000, levando em consideração que ela apresenta um ponto de vista específico sobre os fatos narrados. É sob essa perspectiva que este trabalho se debruça, utilizando como embasamento teórico os estudos da memória e do urbanismo contemporâneo.

José Fernandes Pedral Sampaio nasceu no ano de 1925 na cidade de Vitória da Conquista, e pertencia a uma das mais importantes e tradicionais famílias da cidade. Durante alguns anos estudou na capital do estado, Salvador, onde formou-se em engenharia civil pela Universidade Federal da Bahia, em 1949. Em seguida, retornou para a sua cidade natal e relatou ter levado consigo uma "metodologia moderna de governar e administrar

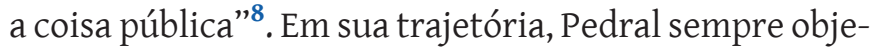
tivou um grande desenvolvimento urbano para Vitória da Conquista, buscando criar infraestruturas e ampliar

\footnotetext{
6. Pollak, 1989, 13.

7. Halbwachs, 1990, 51.

8. Menezes, 2012, 18.
} 
a malha urbana, utilizando-se de referências externas para fundamentar suas decisões políticas.

O político faleceu em 2014, aos 89 anos, portanto, recorre-se neste trabalho, ao relato colhido pela entrevistadora Andreya Nascimento, cujo objetivo, na época, foi investigar as intenções de José Pedral e de seu grupo político, no processo de transferência da Biblioteca Municipal José de Sá Nunes, do centro da cidade, para a região de um antigo açude, que integrava o leito do rio Verruga.

O grupo político de Pedral obteve uma força tão grande no município, que se tornou conhecido como Pedralismo, um movimento com identidade bem definida, logomarca, hino, bandeira e marchinhas ${ }^{9}$. Na fala transcrita abaixo ${ }^{10}$, José Pedral deixa clara a sua influência nos diferentes mandatos da administração municipal entre 1973 e 1992:

\begin{abstract}
"apesar de eu não ser prefeito, em todas as administrações eu tive uma participação grande como assessor desses prefeitos. Desde a eleição de Jadiel que a gente prestou a ele uma assessoria muito grande, como técnico, como engenheiro, além de uma assessoria política. Também foi feito isso com o Raul, foi feito com Murilo. [...] Eu fui secretário de obras de Raul, então aquele projeto do viaduto, do Cristo, a Prefeitura já estava no governo de Raul, mas, como teve uma participação muito grande minha, [...] às vezes eu penso que fui eu que fiz quando na verdade foi numa administração que não tinha Pedral à frente. Mas fui eu que tive a ideia, que fiz o projeto, eu que executei a obra, sendo Raul prefeito, é claro, era ele o comandante, mas, a gente tinha uma participação muito grande na assessoria desses prefeitos"11.
\end{abstract}

Em um cenário de expansão e reordenamento espacial da cidade, iniciado na década de 1920, o rio Verruga não aparece na legislação ou nas atas públicas como elemento relevante na dinâmica urbana até a elaboração do primeiro Plano Diretor Urbano do município em 1976. Nesse primeiro documento de planejamento urbano municipal encontram-se apenas diretrizes que prezam pela preservação da paisagem natural, proteção aos cursos d'água e reservas florestais, e ainda pela a preservação das condições do espaço físico da cidade, não permitindo que o poder público ou o privado realizassem obras que pudessem vir a modificar o clima, desfigurar a paisagem local, gerar poluição ou acelerar o processo de erosão das terras $^{12}$. Infelizmente essas diretrizes nunca foram colocadas em prática pela administração municipal.

\footnotetext{
9. Menezes, 2012, 13.

10. 0 trecho da declaração de José Fernandes Pedral Sampaio é apresentado por Ferraz trazendo a data de 1998.

11. Ferraz, 2001, 41

12. PMVC, 1976, 02.
}

Apesar da precariedade no planejamento urbano da cidade, Pedral demonstrava ter objetivos bem definidos para a área urbana do entorno do rio, desde 1963, como poderá ser visto ao decorrer do presente texto.

O texto encontra-se estruturado em três momentos: o primeiro volta-se para o rio, enfocando a sua importância como fonte de abastecimento de água; o segundo traz as intervenções urbanas projetadas e realizadas em trecho do entorno do rio, no período de que trata este estudo; e o terceiro momento analisa o reflexo das decisões deste importante líder político na malha urbana atual da cidade.

\section{0 rio como fonte de abastecimento}

A fixação das povoações humanas em territórios está intimamente relacionada à disponibilidade de água para abastecimento da população e dos animais na consolidação das comunidades. Porém, com o desenvolvimento tecnológico e com a implantação das redes de abastecimento, ao longo do tempo, os rios e mananciais foram perdendo sua importância dentro das cidades e se tornaram empecilhos à expansão urbana.

No caso de Vitória da Conquista, o arraial inicial foi implantado sobre a bacia do rio Verruga, afluente do Rio Pardo, no Planalto da Conquista (Mapa 1), possuindo uma altitude média superior a 800 metros acima do nível do mar, em uma região semiárida do interior do Nordeste brasileiro ${ }^{13}$.

O desenvolvimento deste núcleo urbano se deu margeando o leito do rio, e sua principal nascente está situada atualmente na área central da cidade, em uma Reserva Ambiental denominada Poço Escuro (Mapa 2). O rio Verruga e suas nascentes constituíram-se em fonte única de abastecimento de água da cidade de Vitória da Conquista até o final da década de 1960, fosse por meio do lençol freático superficial, ou fosse coletando a água diretamente na nascente.

O primeiro mandato de Pedral como prefeito do município de Vitória da Conquista foi em 1963, mas sua vida política se iniciou em 1958, quando participou do seu primeiro pleito como candidato à prefeitura da cidade. Conforme seu relato, "em Conquista nesta época quem mandava era o coronel, ainda era uma cidade completamente perdida aqui no sertão"14. Quando assumiu a prefeitura, José Pedral explica que encontrou

\footnotetext{
13. Superintendência de Estudos Econômicos e Sociais da Bahia (SEI), 2015, 13.

14. Pedral, 2000, 21.
} 


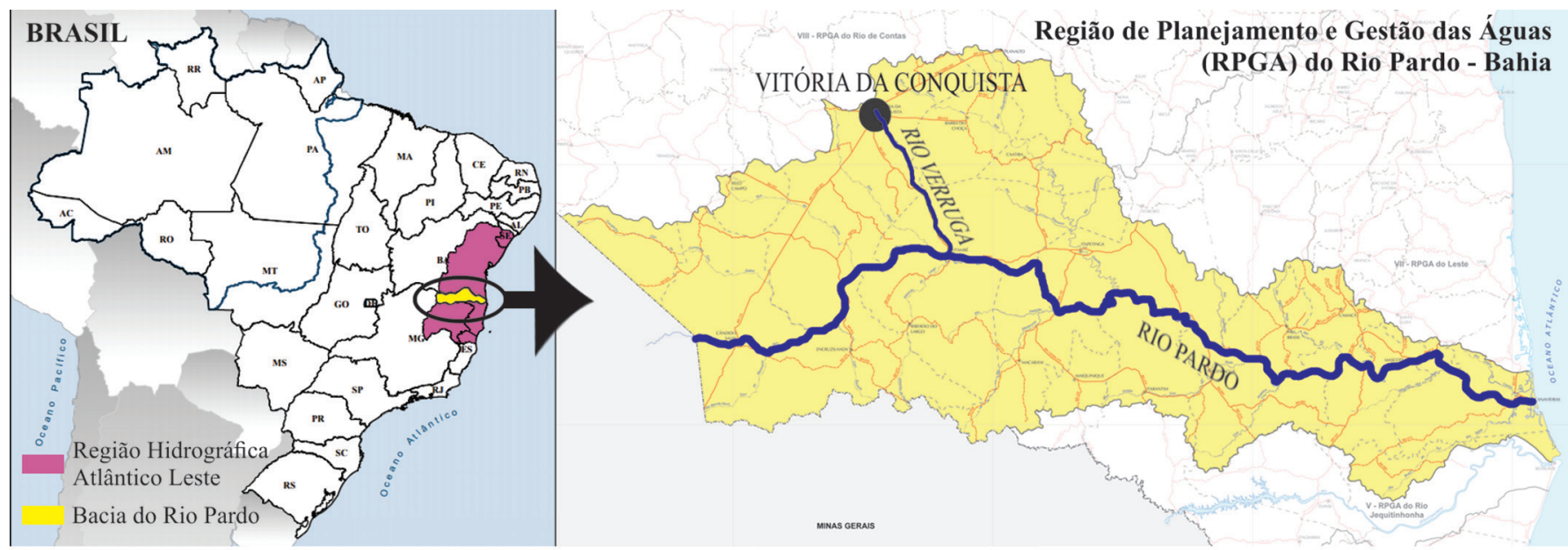

Fonte: Elaborado pela autora, a partir de Agência Nacional de Águas e Saneamento Básico (ANA) - https://www.ana.gov.br/todos-0s-documentosdo-portal/documentos-spr/mapas-regioes-hidrograficas/atlantico-leste-para-site-ana-a0.pdf (acesso em 26 de julho de 2020) - e Instituto do Meio Ambiente e Recursos Hídricos (INEMA) - http://www.inema.ba.gov.br/wp-content/files/VI-RPGA-DO-RIO-PARDO.pdf (acesso em 26 de julho de 2020).

uma cidade rudimentar e pouco desenvolvida, se comparada à sua estadia na capital baiana,

"Conquista nesta época era uma cidade muito pequena, mas pequeníssima mesmo. Não tinha energia elétrica, tinha um motor de trezentos cavalos. Água todo mundo tinha, pois era uma cisterna dentro de cada casa para apanhar água ou comprava do Poço Escuro, água perigosa. Não tinha absolutamente nada: telefone, transportes rodoviários, empresas de ônibus, hotéis, nada" ${ }^{\text {15 }}$.

No trecho acima, pode-se perceber a importância do rio Verruga para o abastecimento da cidade e a forma como se dava o acesso à água, que, muitas vezes, precisava ser comprada. O jornalista Anibal Lopes Viana explica que, no início do século XX, a água da nascente era explorada por "aguadeiros", homens que carregavam a água da nascente para vender, conduzindo-a em recipientes sobre jumentos ${ }^{16}$. Porém, o ex-prefeito se refere à água do Poço Escuro como "água perigosa". Para se analisar essa denominação, é necessário avaliar como a população tinha acesso à água do rio Verruga.

Em 1918, iniciou-se a intervenção do poder público municipal na nascente do Poço Escuro, quando, no governo do intendente Coronel José Maximiliano Fernandes de Oliveira, foi construída a fonte pública Água de Nossa Senhora, que ficou conhecida como "caixa d'água" ${ }^{17}$. Em matéria publicada no Jornal Avante, em 6 de junho de
Mapa 2. Mapa da Expansão urbana no entorno do rio Verruga até 1940

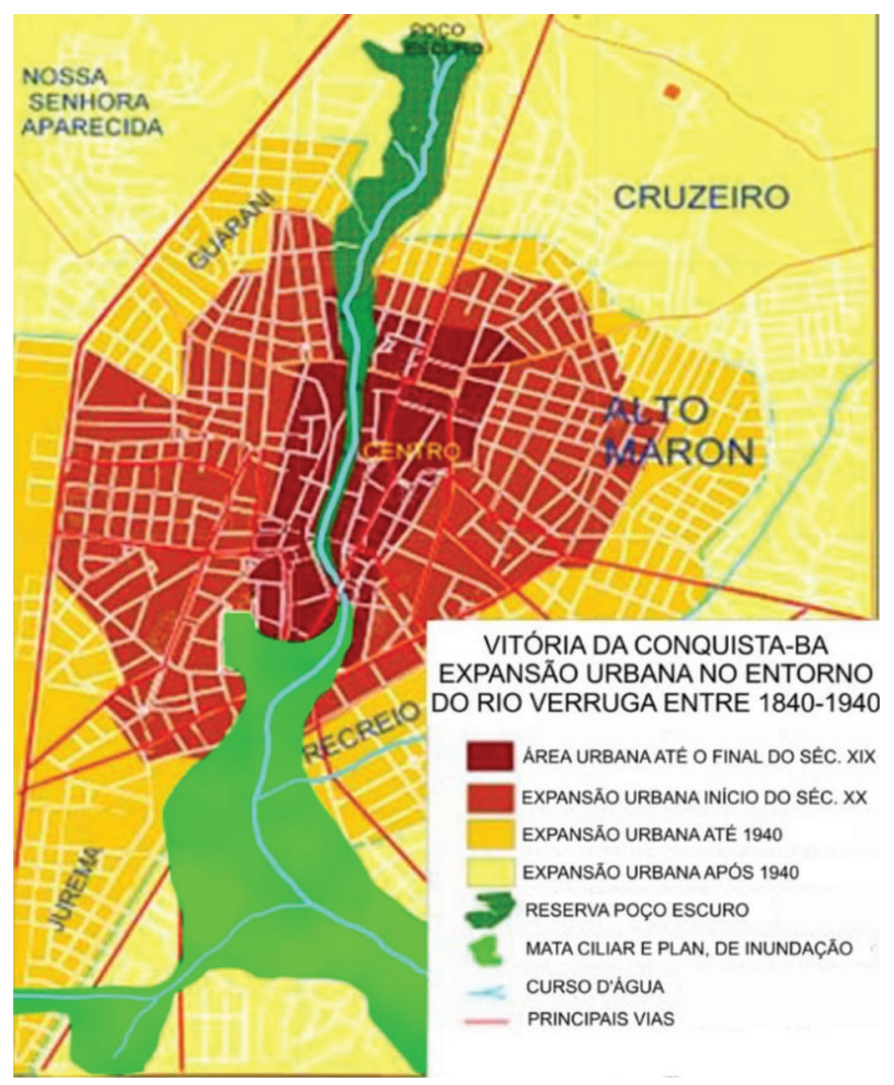

Fonte: Rocha, 2008 -com ajustes gráficos da autora.

\footnotetext{
15. Pedral, 2000, 21-22.

16. Viana, 1985,554

17. Viana, 1985, 552.
} 
1931, percebe-se como esse equipamento não recebeu o devido cuidado por parte da administração municipal:

"O abandono das administrações condemnou este próprio do município a quase desapparecer. E a caixa d'água foi se estragando, a ponto do povo quase interno da cidade, preferir as águas das cisternas às águas de Nossa Senhora da Vitória, da fonte pública, isto devido a immundicie que se notava mormente no córrego que, do poço escuro conduz a água para ás torneiras da caixa" $\left[\right.$ sic $^{18}$.

Segundo Rocha, era grande a quantidade de reclamações nos jornais sobre a situação de abandono da Caixa d'água, relatando que a população pobre que habitava o local depositava os seus dejetos diretamente na nascente ${ }^{19}$, o que expõe a disputa existente entre as diferentes classes sociais pelo uso da água. Mesmo com todas as dificuldades apresentadas, o rio Verruga ainda se constituía a única fonte de abastecimento de água da cidade e as intervenções do poder público seguiram explorando suas águas.

No primeiro mandato de Pedral, em 1963, uma das ações, que ele relata como das mais importantes, se constituiu em uma intervenção no fluxo natural do rio, direcionando parte de suas águas para regiões desabastecidas: “A gente bombeou água lá de baixo, do Poço Escuro para o Alto Maron pelo chafariz, pois o pessoal lá não tinha água. Era difícil fazer cisterna e iam buscar água no Poço Escuro, depois a gente passou a pegar no chafariz" ${ }^{20}$.

O bairro do Alto Maron se situa em cota mais elevada que o centro da cidade e, por esse motivo, o lençol freático possui um acesso mais difícil, sendo necessárias tubulações mais profundas para a captação de água. Naquele momento da história de Vitória da Conquista, essa captação era quase sempre inviável. Portanto, esse e os outros chafarizes se constituíram na principal fonte pública de abastecimento de água da cidade até a efetivação do sistema por água encanada proveniente de barragem construída no rio Água Fria, situado no município vizinho, pelo convênio firmado entre a prefeitura e o Departamento de Engenharia Sanitária do Estado da Bahia - DESEB - através da Resolução no 76/65, que teve sua inauguração em $1971^{21}$. Mesmo após a implantação da rede de água encanada, em períodos de seca e falta d'água, "muitos se socorrem da água do Poço Escuro"22.

\footnotetext{
18. A caixa d'água, 1931 em Rocha, 2011, 138-139.

19. Rocha, 2011, 139.

20. Pedral, 2000, 22.

21. Viana, 1985,554

22. Medeiros, 2015.
}

Apesar de o rio Verruga fornecer toda a água consumida na zona urbana de Vitória da Conquista até o final da década de 60, seu curso era pouco visível pelas ruas da cidade. Dois aspectos podem ser destacados aqui. o primeiro é que, na conformação da cidade, as casas se dispuseram às margens do rio, de forma que seu leito corria pelos fundos das casas e só podia ser acessado em alguns lugares específicos, que foram deixados "em benefício daqueles que não conseguiram ocupar espaço ribeirinho"23. O segundo aspecto é que, nesses locais deixados para acesso ao rio, foram criadas ruas e o rio precisava ser transposto por pontilhões improvisados, e, ainda na primeira metade do século XX, direcionado para canais subterrâneos. Dessa forma, o rio Verruga passou a ser visível apenas no trecho imediatamente após a nascente, no Poço Escuro, e depois apenas aparecia após cruzar a cidade, em uma barragem denominada Aguão.

\section{Intervenções no curso do rio}

Logo após cruzar o centro da cidade de Vitória da Conquista, o curso do rio Verruga encontra uma planície de inundação (Mapa 2). Trata-se de uma região alagadiça, onde, no período de governo do Intendente João Diogo de Sá Barreto -entre 1906 e 1908- construiu-se uma barragem, represando as águas do rio e configurando um açude permanente (Imagem 1 ). Sobre essa área, Pedral rememora:

“Esse rio já foi muito grande, no tempo do meu avô se pescava nesse rio, aqui na praça 9 de novembro, hoje é canalizado, mas se pescava ali, e fizeram um açude onde hoje é a Praça Bartolomeu de Gusmão. Em 64 eu destruí essa barragem, pois a região tinha muita esquistossomose, por causa da barragem"24.

Através desse relato, pode-se perceber a forma com a qual o rio Verruga se apresenta na memória de quem o vivenciou, direta e indiretamente. A lembrança deste rio remete ao início do século XX, e o mostra como marco fundamental da cidade, não apenas como fonte de abastecimento de água, mas também como objeto de lazer e de provisão de alimentos.

A canalização do trecho urbano do rio, com seu respectivo tamponamento, e o rompimento da barragem do açude marcaram a história do rio Verruga, e deram início a um período de crescente invisibilidade daquele curso d'água.

\footnotetext{
23. Medeiros, 2015.

24. Pedral, 2000, 25.
} 
Imagem 1. Açude de Vitória da Conquista

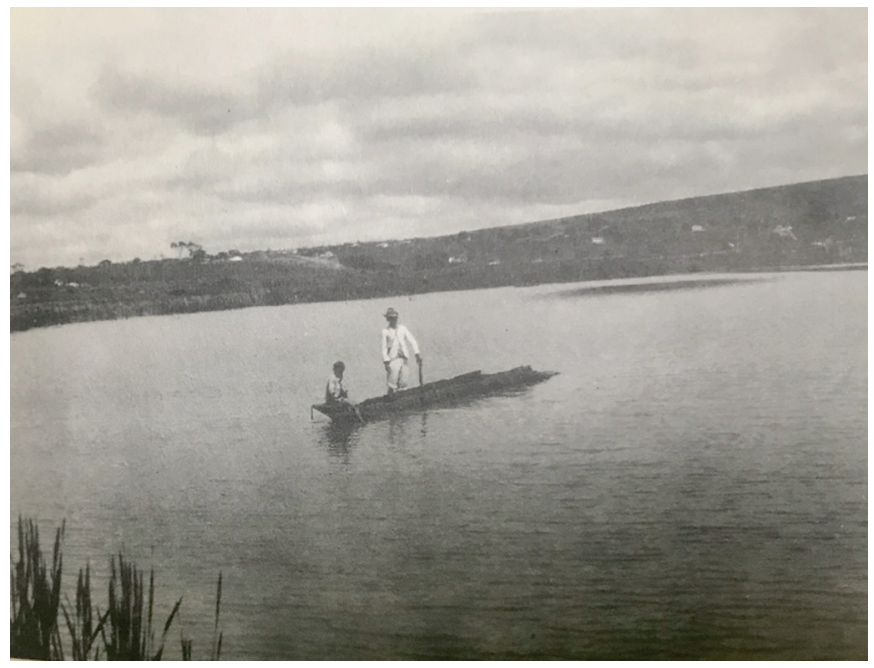

Fonte: Rocha, 2020.

Essas primeiras intervenções no leito do rio seguiam as técnicas contemporâneas do urbanismo higienista, surgidas na segunda metade do século XIX na Europa. Após a epidemia de Cólera em Paris, iniciada em 1832, o pensamento urbanístico sofreu uma intensa transformação, gerando grandes intervenções nas cidades europeias, quando se buscava "acelerar as trocas e os fluxos", "multiplicar as 'aberturas", "liberar os espaços" e "ampliar os circuitos da água" 25 , tendo como expoente a reforma urbana de Haussmann em Paris. Trazidas ao Brasil ainda no final do século XIX, as ideias do urbanismo higienista se traduziam no "alargamento de ruas para propiciar ventilação nas moradias e obras que visavam à eliminação de áreas úmidas e alagáveis, também dando fim aos dejetos que eram jogados nas vias públicas" ${ }^{26}$. As cidades passaram a ser drenadas "não mais na superfície, mas em profundidade por um sistema de canalizações soterradas"27.

O Rio de Janeiro e São Paulo foram as primeiras cidades brasileiras a apresentar as intervenções desse novo modelo urbanístico. São Paulo, expoente da economia cafeeira brasileira à época, viu suas várzeas e seus cursos d'água serem transpostos nos primeiros anos do século XX, gerando oportunidades de investimento nos novos terrenos criados após o tamponamento e a retificação, em consonância com as linhas do sistema capitalista em consolidação no Brasil ${ }^{28}$.

Em Vitória da Conquista não aconteceu diferente: a partir de 1940, presenciaram-se sucessivas intervenções no leito do rio Verruga e em sua planície de inundação (Mapa 3), gerando novos terrenos para a expansão urbana e ocultando cada vez mais as suas águas, que passaram a ser vistas pela população como uma mazela.

$\mathrm{Na}$ linha das medidas higienistas, com o objetivo de reduzir a incidência de doenças no núcleo urbano, Pedral traz a referência à prevalência da esquistossomose em Vitória da Conquista como justificativa para o rompimento da barragem do rio Verruga. A esquistossomose já havia sido diagnosticada na Bahia desde o início do século XX, tendo sido realizado no país um estudo mais específico no período entre 1947 e 1952, onde estimou-se que 2,6 milhões de pessoas eram portadoras da infecção, e identificou-se que a grande maioria dos casos estavam na região nordeste do país, com participação significativa da Bahia nesse total ${ }^{29}$.

É a partir do rompimento da barragem, na fase inicial da administração de Pedral, que se encontra o fato estruturante da entrevista aqui analisada. Quando se refere ao antigo açude, o ex-prefeito deixa claro que:

“essa área era pra ser um parque, não se concretizou o projeto, mas é para ser um parque. Isso foi em 1964 e está até hoje. Ninguém fez mais nada. Já foi feito no bairro Jurema e também vai chegar a hora de fazer esse canal e ali será um parque, parecido com a da Praça da República em São Paulo. Essa biblioteca estará dentro de um parque no dia que se fizer esse trabalho. Será uma coisa linda, com pássaros cantando, aí vai ser bom, tudo arborizado no futuro. Isso está pronto no projeto, basta apenas tomar posse. Essa moçada de hoje não conhece muito do passado, é preciso registrar essa memória sim" ${ }^{\text {"30 }}$.

Os planos que foram rememorados por Pedral, quando questionado sobre a transferência da biblioteca municipal para a área alagadiça remanescente do antigo açude, configuram um ideal de cidade que não foi concretizado nos 24 anos posteriores ao rompimento da barragem em que ele $\mathrm{e}$ seu grupo político estiveram à frente do poder municipal.

Talvez a transferência da biblioteca, em 1991, na gestão do prefeito Murilo Mármore, pertencente ao seu grupo político, significasse para Pedral um importante passo em seu projeto de implantação do citado parque, que começou a ser idealizado em 1963. Logo após assumir o seu primeiro mandato na administração municipal, José Pedral assinou, em agosto de 1963, um decreto

\footnotetext{
25. Vigarello, 1996, 18.

26. Herzog, 2013, 42.

27. Vigarello, 1996, 20.

28. Santos, 2018, 48-49.
}

\footnotetext{
29. Barbosa et al., 2008, 979-980.

30. Pedral, 2000, 26.
} 
Mapa 3. Canalização e aterramento do rio Verruga

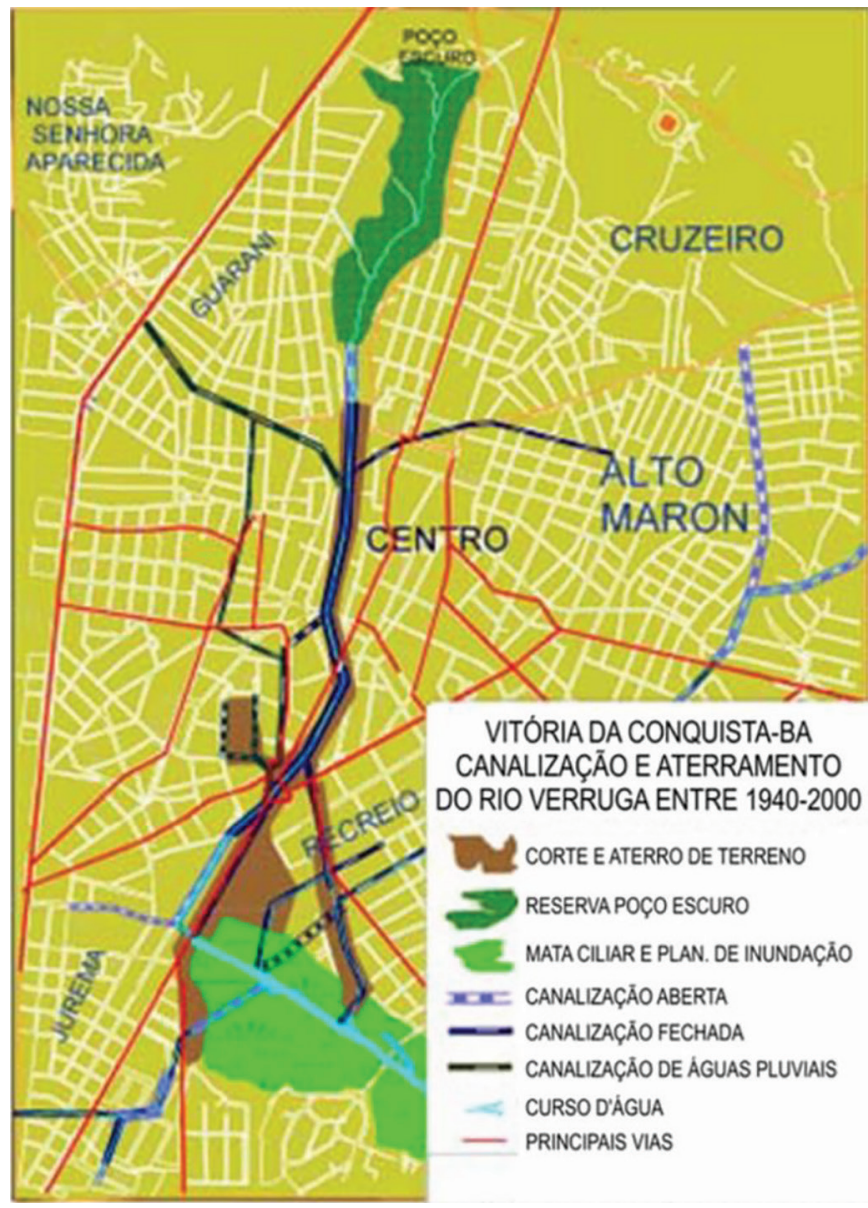

Fonte: Rocha, 2008 -com ajustes gráficos da autora.

delimitando uma área pública às margens do ainda existente açude, no qual destacam-se os seguintes trechos:

"Considerando que o açude denominado "Aguão" não vem sendo utilizado como fonte de abastecimento da Cidade e que não mais atende a finalidade para a qual foi construído - bebedouro para animais;

Considerando que, atualmente, o referido açude nada mais significa do que um terrível foco de doenças e mosquitos, e que o seu saneamento é praticamente impossível, vez que as águas de todos os esgotos da Cidade para êle [sic] confluem;

Considerando, também, a vantagem de ser construído um parque, no qual serão plantadas e criadas árvores tropicais, pois a área verde da Cidade é mínima;

[...]

Art. $2^{\circ}$ - A Prefeitura promoverá a ocupação dos terrenos situados na área do polígono determinado no artigo $1^{\circ}$ do presente Decreto, depois de cumpridas as formalidades legais a fim de na referida área, construir várias obras de interêsse [sic] público, bem como efetuar o plantio de árvores tropicais"31.
Grandes parques nos núcleos urbanos constituíam premissas relevantes no urbanismo modernista do início do século XX, porém, diversos parques no Brasil foram implantados seguindo o padrão dos jardins norte-americanos e europeus ${ }^{32}$, não se preocupando com as características locais dos terrenos em que seriam implantados. Da mesma forma, Pedral pretendia implantar o parque do rio Verruga, com o plantio de nova vegetação e a modificação das características naturais do local como uma planície de inundação, trazendo como referência em sua fala a Praça da República de São Paulo, cujo desenho francês busca disciplinar a natureza em ambientes controlados.

A consolidação desse parque, no primeiro mandato de Pedral, dependeria de diversos fatores de ordem jurídica, política e econômica, que não puderam ser colocados na pauta de ações da prefeitura, naquele momento, devido à cassação do mandato do prefeito em 1964 após a ascensão dos militares ao governo brasileiro, que deu início ao período da Ditadura Militar, com intensa perseguição ao pensamento político de esquerda no país, como era o caso do pensamento de José Pedral. Após ser preso e ter os seus direitos políticos suspensos, o ex-prefeito foi obrigado a se afastar diretamente da prefeitura por quase 20 anos $^{33}$. Neste cenário, suas atividades passam a ser de articulação política, conforme relato a seguir:

"Então eu passei a viver num escritório, calculando concreto armado e fazendo construção para particulares, porque para o governo, para o poder público eu não podia fazer. Durante esse tempo a gente organizou uma equipe muito boa, disputando as eleições. Disputamos com Gilberto Quadro e perdemos, mas ganhamos com o Jadiel Matos, Raul, isso em função do grupo que tínhamos formado; primeiro para resistir à ditadura e segundo para que Conquista continuasse naquele caminho de desenvolvimento, de crescimento e de progresso. A gente passou a ver que tinha muito para construir, o aeroporto, as estradas, a Universidade, por mim e pelos outros prefeitos que fizeram parte deste grupo político"34.

Mesmo com os direitos políticos suspensos, Pedral relata a importância da organização do seu grupo para resistir ao autoritarismo dos militares e tentar manter a continuidade das políticas públicas idealizadas por ele para o município. Sua articulação política foi, em parte, exitosa, pois os Pedralistas conseguiram estar à frente da prefeitura durante os 10 últimos anos do regime mi-

\footnotetext{
32. Herzog, 2013, 55.

33. Menezes, 2012, 258-259.

34. Pedral, 2000, 25.
} 
litar, de 1973 a 1983, mas enquanto Pedral demonstrava estar direcionando os seus esforços na disputa contra o regime político instalado, o rio Verruga vivenciava um crescente esquecimento por parte da população e dos governantes da cidade.

Foi nesse período que a cidade teve a sua maior expansão populacional, e que o rio deixou de ser fonte de abastecimento, uma vez que seu volume de água já não era mais suficiente para suprir a necessidade dos mais de 85.000 habitantes da zona urbana na década de $1970^{35}$. 0 local do antigo açude, já drenado, passou a ser ocupado, paulatinamente, pelos proprietários das áreas adjacentes e recebeu novas vias públicas, que ampliaram o solo ocupável da cidade sobre a antiga planície de inundação.

Paralelamente a essa mudança de função, com o crescimento urbano, verificou-se uma intensificação no direcionamento dos esgotos in natura e lixo para o leito do rio Verruga $^{36}$, uma vez que a rede de esgotamento sanitário só teve sua construção iniciada em $1974^{37}$ e avançou de forma lenta ao longo dos anos seguintes. Verifica-se, no Plano Diretor Urbano de 1976, a regulamentação nas ligações dos esgotos secundários das residências, comércios e indústrias -e, em algumas situações, inclusive do esgoto primário- à rede pública pluvial por conta da inexistência da rede pública de esgotamento sanitário ${ }^{38}$. 0 direcionamento dos dejetos, em volumes cada vez maiores, tornou o rio Verruga extremamente poluído e fez das suas margens ambientes inóspitos.

Contudo, ao falar do local escolhido em 1991 para a construção da nova biblioteca municipal -um terreno alagadiço, que tem como função natural a captação da água da chuva- a rememoração de José Pedral nos direciona para outro aspecto:

"O local escolhido para construir a atual biblioteca é muito adequado sim. $\mathrm{E}$ citei os dois exemplos o do Cristo e o do Ginásio Raul Ferraz, para exatamente dizer que houve uma resistência muito grande na época, mas se olhar no mapa da cidade, a biblioteca está no centro da cidade, o que está faltando e que não foi feito, foram as vias de acesso melhores, e o serviço de drenagem.

Pois o que se tem feito lá é somente escavas as valas [sic], no dia em que for feito um canal grande ali, aquilo seca completamente como o Jurema que era grande charco, nós drenamos o Jurema, fizemos uma tubulação grande e o problema acabou. Lá no bairro Brasil fizemos uma drenagem muito grande. Mas no dia em que se dre-

\footnotetext{
35. Ferraz, 2001, 37.

36. Medeiros, 2015 .

37. Viana, 1985,555

38. PMVC, 1976 .
}

nar isso aí temos tal projeto, esse projeto que se chama Aguão, será uma área verde muito grande e a biblioteca ficará dentro de um bosque, vegetação linda, que chegará esse dia de fazer"39.

Além da questão da destinação da referida área para um parque, salienta-se também outra política urbana bastante comum em meados do século XX, quando o pensamento urbanístico orientava à canalização e tamponamento de rios urbanos, objetivando espaços mais amplos e monumentais. Porém, ainda no século XIX, o arquiteto paisagista Frederick Law Olmsted iniciou as bases para o planejamento ecológico, que se distinguia do padrão dos parques europeus, ao objetivar a conservação de áreas naturais em grandes cidades norte americanas, onde se podiam manter os fluxos naturais da água, mas suas premissas apenas se tornaram referência ao urbanismo na segunda metade do século $\mathrm{XX}^{40}$. Atualmente já se reconhece que a drenagem, o aterramento e a canalização dos cursos d'água acarretam uma intensificação das inundações urbanas, que exigem infraestruturas cada vez mais onerosas e que apenas transferem o problema para outras áreas do curso d'água.

A partir do momento em que o rio Verruga foi retirado da vista da população citadina, a poluição neste curso d'água atingiu níveis alarmantes, afastando cada vez mais a vida urbana das suas margens em um movimento cíclico. Nesse cenário de crescente rejeição ao rio, ocorreu a transferência da biblioteca municipal para a área do esquecido "Aguão" (Imagens 2 e 3), fato que ocasionou uma diminuição relevante no número de visitas ao equipamento, gerada em grande parte pelo difícil acesso à região. Em seu relato, o prefeito reconhece: "Não pensei que a biblioteca fosse ficar localiza-

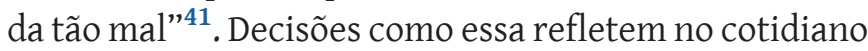
da população e afetam diretamente a relação entre a cidade e os seus habitantes.

\section{0 poder das decisões e 0 reflexo no espaço urbano}

Mas, afinal, o que deve ser considerado ao se tomar uma decisão que impactará a vida de milhares de pessoas? Quando se fala em espaço urbano, não se pode menosprezar o fato de que as paisagens se modificam em uma velocidade diferente da vivenciada pelos seres humanos.

\footnotetext{
39. Pedral, 2000, 23-24.

40. Herzog, 2013, 43-44

41. Pedral, 2000, 25.
} 
Imagem 2. Biblioteca municipal inserida na área do Aguão

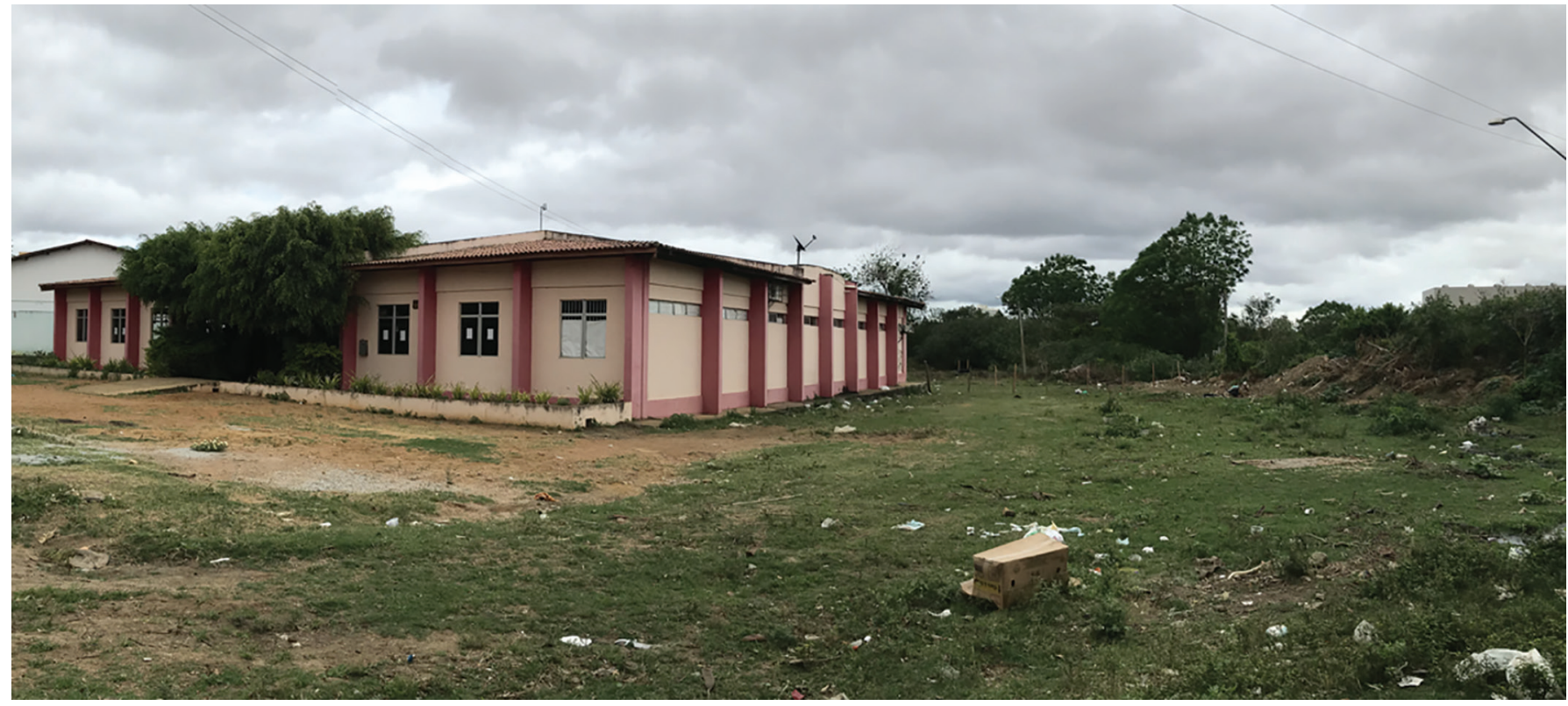

Fonte: Acervo pessoal, 2020.

Imagem 3. Área remanescente do Aguão

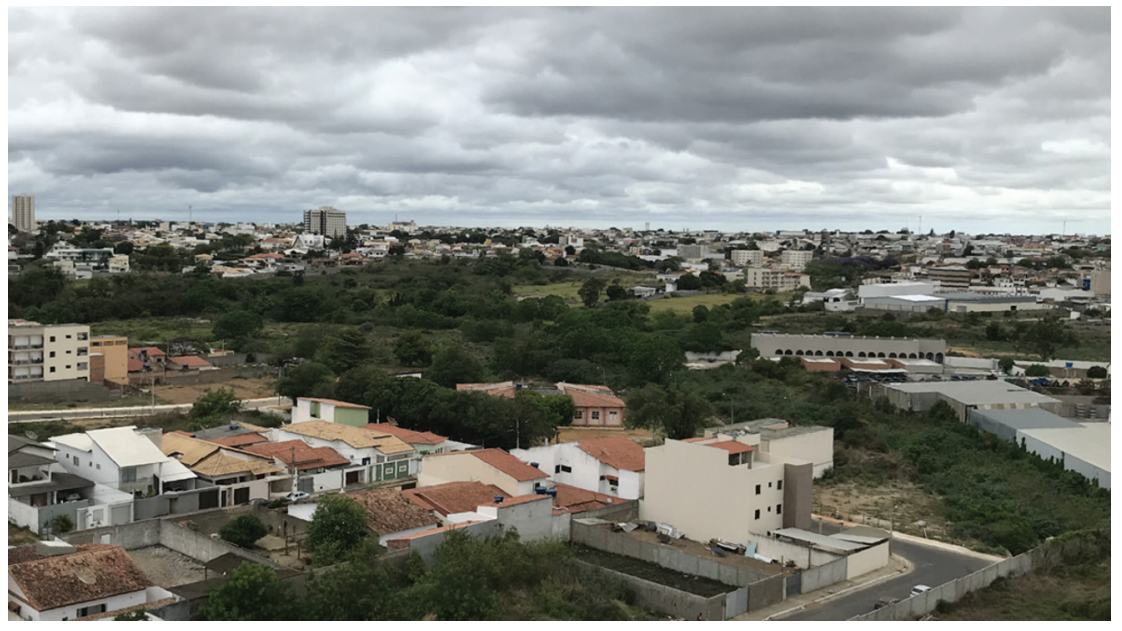

Fonte: Acervo pessoal, 2020.

Aleida Assmann, ao tratar da memória dos "locais", "aponta para a possibilidade de que os locais possam tornar-se sujeitos, portadores da recordação e possivelmente dotados de uma memória que ultrapassa amplamente a memória dos seres humanos" ${ }^{42}$. 0 entendimento de Assmann leva à percepção da paisagem urbana como uma personagem atuante que afeta uma memória mais ampla, ancorando essa memória no chão e corporificando "uma continuidade da duração que supera a recordação relativamente breve de indivíduos" 43 .

\footnotetext{
42. Assmann, 2011, 317.

43. Assmann, 2011, 318.
}

É sobre essa mesma tese que Maurice Halbwachs havia se debruçado algumas décadas antes. Para ele, os espaços físicos, por se modificarem em uma velocidade muito menor que a sociedade, são um referencial de estabilidade em uma espécie de "sociedade silenciosa e imóvel, estranha à nossa agitação e às nossas mudanças de humor que nos dá uma sensação de ordem e de quietude" ${ }^{44}$, permitindo que os indivíduos se reencontrem consigo. Assim, o sociólogo traz que "o grupo urbano não tem a impressão de mudar enquanto o aspecto das ruas e dos edifícios permanece idêntico, e que há poucas

\footnotetext{
44. Halbwachs, 1990, 131.
} 
formações sociais ao mesmo tempo estáveis e ainda seguras de permanecer" 45 .

Dessa forma, torna-se fundamental compreender que as decisões tomadas pelo poder público na esfera da urbe marcarão profundamente a memória e a identidade de determinada população que se relaciona com aquele local. Recorrendo a Pollak, temos que,

"nenhum grupo social, nenhuma instituição, por mais estáveis e sólidos que possam parecer, têm sua perenidade assegurada. Sua memória, contudo, pode sobreviver a seu desaparecimento, assumindo em geral a forma de um mito que, por não poder se ancorar na realidade política do momento, alimenta-se de referências culturais, literárias ou religiosas. 0 passado longínquo pode então se tornar promessa de futuro e, às vezes, desafio lançado à ordem estabelecida" ${ }^{n 46}$.

No caso de Vitória da Conquista, a memória da atuação do grupo Pedralista segue viva na malha urbana da cidade, e não se encontra muito claro o critério que foi utilizado pela administração municipal para tomar importantes decisões no processo de conformação urbana, incluindo a não implantação do projeto do parque durante os governos posteriores de José Pedral. O ex-prefeito argumenta, em sua entrevista, que "não existe nada que um prefeito faça que não mereça crítica. É preciso então que se tenham argumentos para justificar o que se faz" ${ }^{47}$. Ao mesmo tempo, afirma ter objetivado "mudar completamente os métodos do governo" anterior, e garante: "voltada para o povo, uma administração democrática isto a gente conseguiu" 48 .

A Legislação Brasileira apenas passou a considerar como essencial uma "gestão democrática", no que diz respeito a decisões de configuração do espaço urbano, no ano de 2001 -data posterior ao relato de José Pedral analisado neste trabalho- através da promulgação da Lei Federal denominada Estatuto da Cidade. Nesta Lei, é estabelecido o conceito e instrumentos de gestão democrática da cidade, tendo como base a participação atuante da comunidade em todo o processo de desenvolvimento urbano ${ }^{49}$. Antes dessa data, como é o caso das administrações municipais estudadas nesse texto, não se sabe quais os instrumentos utilizados para garantir a gestão democrática da cidade.

\footnotetext{
45. Halbwachs, 1990, 134.

46. Pollak, 1989, 11.

47. Pedral, 2000, 24.

48. Pedral, 2000, 21.

49. Brasil, 2001.
}

Analisando-se os reflexos das decisões de rompimento da barragem do açude, da não implantação do parque pretendido por Pedral, e da transferência da biblioteca municipal para a área em questão, verifica-se que a região remanescente do antigo açude se configurou como um vazio urbano imerso, atualmente, no centro da cidade (Mapa 4), e a biblioteca segue à espera de uma intervenção urbana que a coloque novamente como o importante equipamento público que já foi um dia quando situada em outra edificação.

A natureza, por sua vez, não espera, e segue seu curso, tentando se recuperar dos efeitos nocivos das ações do ser humano, gerando nesse processo incontáveis prejuízos aos habitantes da cidade, que continuam sofrendo com as inundações causadas pelo tamponamento do rio e de sua várzea, e que não mais se identificam com o curso d'água do qual um dia já se abasteceram. As áreas que foram aterradas e ocupadas por construções, inclusive a biblioteca municipal, antes pertencentes à planície de inundação, sofrem constantes inundações nos períodos anuais de chuvas, com relevante destruição, uma vez que a elas confluem todas as águas de drenagem superficial provenientes das vias que descem a Serra do Periperi.

A política de drenagem urbana recorre sempre, com olhar isolacionista, aos sistemas artificiais que se mostram insuficientes, criando paulatinamente problemas na jusante do rio, devido ao volume e velocidade com os quais as águas que correm pelas galerias chegam às partes mais baixas do rio, sem resolver por completo as enchentes na região central da cidade.

A maioria das cidades do mundo que aplicaram as reformas urbanas, inspiradas no modelo de Haussmann, com canalização dos rios e aterramento de áreas alagáveis, convivem com problemas de inundações até hoje, devido às alterações na estrutura hídrica com o bloqueio dos fluxos naturais ${ }^{50}$. É preciso adotar novas formas de convivência harmônica com os cursos naturais da água, que já podem ser vivenciadas em diversas cidades do mundo que aplicam o Desenvolvimento Urbano de Baixo Impacto-LID (Low Impact Development). Os princípios do LID têm sido adotados por algumas poucas cidades brasileiras nas últimas décadas, eles se baseiam na conservação de processos hidrológicos, prevenção à poluição do solo e das águas, e preservação de recursos naturais, minimizando a construção de sistemas artificiais ${ }^{51}$.

\footnotetext{
50. Herzog, 2013, 48.

51. Souza, Cruz e Tucci, 2012.
} 
Mapa 4. Áreas não ocupadas no trecho urbano consolidado do rio Verruga

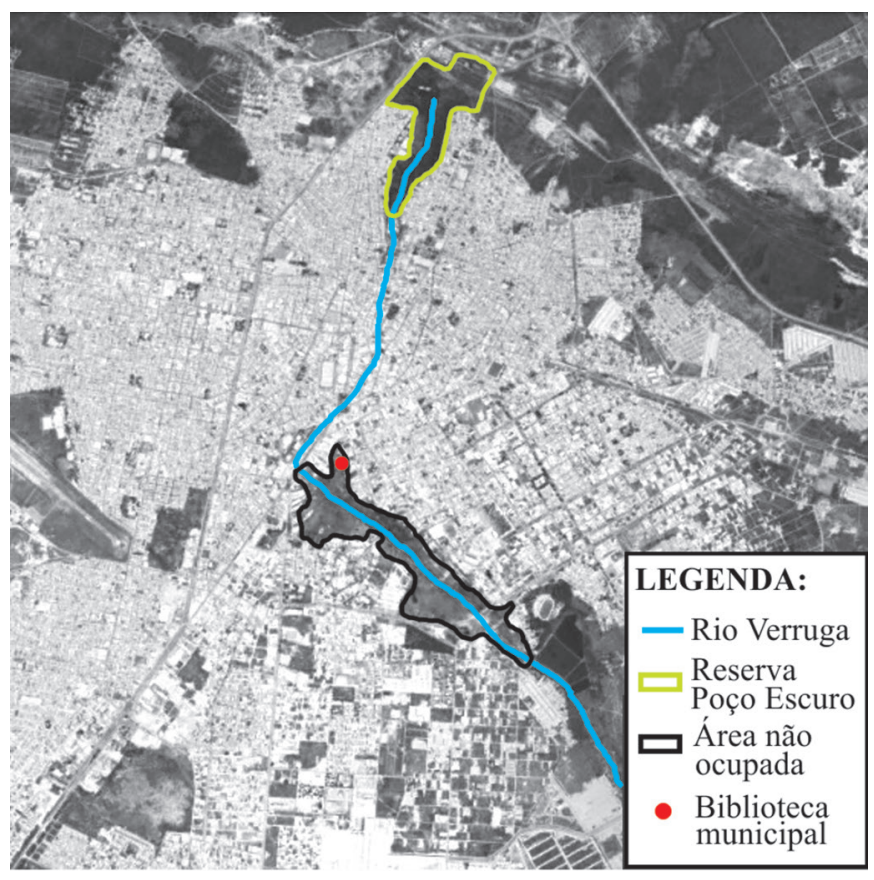

Fonte: Elaborado pela autora, a partir de Google Earth e Vitória da Conquista, 2019.

Em Vitória da Conquista, o rio Verruga ainda é visto como uma mazela, o responsável pela destruição causada nos períodos de chuva e pelo forte odor que exala de suas águas, incomodando e trazendo doenças para a população.

\section{Considerações finais}

Através de uma experiência concreta, o depoimento de história oral aqui analisado mostra um exemplo ilustrativo da incapacidade do poder público em lidar com os elementos e fluxos da natureza na construção das cidades durante o século XX. Verifica-se que a relação estabelecida entre a expansão urbana e os elementos da paisagem natural, no período considerado, não se mostrou sustentável a longo prazo e que, portanto, é preciso adotar outras formas das cidades brasileiras se relacionarem com os rios urbanos.

As decisões tomadas por Pedral entre 1963 e 1996 -e aquelas que foram preteridas- seguem hoje refletidas na malha urbana de Vitória da Conquista, o que nos leva à conclusão de que mesmo as ações pontuais do poder público têm papel decisivo no futuro das dinâmicas urbanas.

A entrevista de José Pedral, mais que justificar a implantação da biblioteca, remete a um ideal de cidade que não foi alcançado por sua administração. Destaca-se que, ao contrário do que Pedral demonstrava ter como objetivo para o entorno do rio Verruga, as ações do grupo Pedralista acarretaram uma ênfase da imagem negativa do rio frente à sociedade. As mazelas provenientes deste curso d'água se tornaram o foco principal, se fixando na memória coletiva como uma área degradada, um esgoto a céu aberto, responsável pela transmissão de doenças e por enchentes constantes. Mais recentemente, para os imigrantes que se estabeleceram na cidade nas últimas décadas, a existência do rio Verruga é desconhecida, prevalecendo o esquecimento do curso d'água que, há 50 anos, era a principal fonte de abastecimento.

Frente a essa realidade, se torna fundamental refletir sobre o futuro do rio e do seu entorno sempre olhando, e aprendendo, com o passado. Cabe às gerações futuras de governantes o desafio de ressignificar essa memória, sob a luz de um novo tempo, visando a uma melhoria na qualidade de vida na cidade. Para se pensar o futuro da cidade, é necessário voltar-se para os ensinamentos do processo histórico no desenvolvimento urbano, compreendendo os desafios da realidade atual e estando atento ao contexto no qual as decisões que interferem na escala urbana são tomadas, de forma que as cidades não fiquem submetidas aos projetos políticos de cada governante individualmente. Com as experiências que as sociedades puderam vivenciar nas diversas cidades do mundo durante o século XX, hoje têm-se a consciência de que é fundamental ter um planejamento urbano mais amplo, um projeto de cidade em contínua atualização, com uma visão de futuro construída de forma coletiva. 


\section{BIBLIOGRAFIA}

Assmann, A. 2011: Espaços da recordação: formas e transformações da memória cultural. Campinas (Brasil), Editora da Unicamp.

Barbosa, C. S., Favre, T. C., Amaral, R. S. e Pieri, O. S. 2008: "Epidemiologia e Controle da Esquistossomose Masoni", em Carvalho, O. S., Coelho, P. M. Z. e Lenzi, H. L. (Orgs.), Schistosoma mansoni e Esquistossomose: uma visão multidisciplinar. Rio de Janeiro (Brasil), Editora FIOCRUZ, 965-1008. https://doi. org/10.7476/9788575413708

Brasil. 2001: Lei $n^{0}$ 10.257, de 10 de julho de 2001. Regulamenta os arts. 182 e 183 da Constituição Federal, estabelece diretrizes gerais da política urbana e dá outras providências. Presidência da República, Brasilia. http://www.planalto.gov.br/ccivil_03/leis/leis_2001/ L10257.htm. Consulta realizada em 1 de agosto de 2020.

Ferraz, A. E. Q. 2001: O urbano em construção: Vitória da Conquista: um retrato de duas décadas. Vitória da Conquista (Brasil), UESB.

Halbwachs, M. 1990: A Memória Coletiva. São Paulo (Brasil), Editora Revista dos Tribunais.

Herzog, C. P. 2013: Cidades para todos: (re) aprendendo a conviver com a natureza. Rio de Janeiro (Brasil), Mauad X: Inverde. https://doi.org/10.11606/issn.2179-2275.v0i6p266-266

Instituto Brasileiro de Geografia e Estatística (IBGE) 2020: Regiões de influência das cidades: 2018. Rio de janeiro (Brasil), IBGE. https://biblioteca.ibge.gov.br/visualizacao/livros/liv101728.pdf. Consulta realizada em 1 de agosto de 2020.

Medeiros, R. 2015: Contribuição ao debate sobre o Rio Verruga. Vitória da Conquista (Brasil), Câmara Municipal.

Menezes, D. L. 2012: O Pedralismo um fenômeno social. Vitória da Conquista (Brasil), Brasil Artes Gráficas LTDA.

Pedral, J. 2000: "Memória de Pedral", em Nascimento, A., História e memória da Biblioteca Municipal José de Sá Nunes, Monografia de Graduação, Universidade Estadual do Sudoeste da Bahia, Vitória da Conquista (Brasil).

Pollak, M. 1989: "Memória, Esquecimento, Silêncio". Estudos Históricos, 2 (3), 3-15. http://bibliotecadigital.fgv.br/ojs/index.php/ reh/article/view/2278/1417. Consulta realizada em 7 de fevereiro de 2021.

Prefeitura Municipal de Vitória da Conquista (PMVC), 1963: Decreto $n^{\circ} 10$, de 2 de agosto de 1963. Considera de utilidade pública, para efeito de desapropriação, os bens que especifica. Vitória da Conquista (Brasil).

Prefeitura Municipal de Vitória da Conquista (PMVC), 1976: Plano Diretor Urbano Lei no 118, de 22 de dezembro de 1976. Dispõe sobre o Plano Diretor de Vitória da Conquista. Vitória da Conquista (Brasil).
Prefeitura Municipal de Vitória da Conquista (PMVC), 2019: Plano Estratégico Vitória da Conquista 2020, Etapa I - Planos Diretores de Desenvolvimento Urbano e Agência Reguladora Municipal, Produto 9 Tomo II - Relatório de Diagnóstico Integrado e Cenários do Plano Diretor de Desenvolvimento Urbano. http://www.pmvc. ba.gov.br/wp-content/uploads/PMVC_PDDU_Produto_9_TomoII-\%E2\%80\%93-Relat\%C3\%B3rio-do-Diagn\%C3\%B3stico-Integrado-e-Cen\%C3\%A7 rios-do-Plano-Diretor-de-Desenvolvimento -Urbano-PDDU.pdf. Consulta realizada em 10 de dezembro de 2019.

Rocha, A. A. 2008: Análise socioambiental da bacia do Rio Verruga e os processos de urbanização de Vitória da Conquista-BA, Dissertação de Mestrado, Universidade Federal da Paraíba, João Pessoa (Brasil).

Rocha, E. C. 2011: As fontes dos vestígios: memória e fotografia nas transformações urbanas na cidade de Conquista entre 1920 e 1940, Dissertação de Mestrado, Universidade do Estado da Bahia, Salvador (Brasil).

Rocha, F. P. R. 2020: Conquista, minha Conquista. Vitória da Conquista (Brasil), Gráfica Laser7.

Santos, F. A. 2018: "Intervenções sobre o rio Pinheiros e a incorporação do espaço urbano nas primeiras décadas do século XX: o caso da região do Brooklin na cidade de São Paulo". Agua y Territorio, 11, 44-57. https://doi.org/10.17561/at.11.2953

Santos, M. 1993: A urbanização brasileira. São Paulo (Brasil), HUCITEC.

Souza, C. F., Cruz, M. A. S., e Tucci, C. E. M. 2012: "Desenvolvimento urbano de baixo impacto: planejamento e tecnologias verdes para a sustentabilidade das águas urbanas". Revista Brasileira de Recursos Hídricos, 17 (2), 9-18. https://doi. org/10.21168/rbrh.v17n2.p9-18

Superintendência de Estudos Econômicos e Sociais da Bahia (SEI) 2015: Perfil dos Territórios de Identidade. Volume 01. Salvador, SEl. https://www.sei.ba.gov.br/index.php?option=com_conten t\&view $=$ article\&id $=2000 \&$ ltemid $=284$. Consulta realizada em 1 de agosto de 2020.

Viana, A. L. 1982: Revista Histórica de Conquista. Volume 1. Vitória da Conquista, 0 Jornal de Conquista.

Viana, A. L. 1985: Revista Histórica de Conquista. Volume 2. Vitória da Conquista, 0 Jornal de Conquista.

Vigarello, G. 1996: "O trabalho dos corpos e do espaço". Projeto História, 13, 7-20. https://revistas.pucsp.br/index.php/revph/article/view/17254/8262. Consulta realizada em 7 de fevereiro de 2021. 